\title{
Photosynthesis engineered to increase rice yield
}

\author{
An engineered increase in Rubisco production has increased photosynthetic capacity, rice yield and nitrogen use \\ efficiency in an experimental paddy field. This demonstrates a key means to sustainably increasing yield and global \\ food security.
}

\section{Stephen P. Long}

ngineered increases in photosynthetic activity has, in recent years, improved crop productivity under field production conditions ${ }^{1}$, but not in our most important source of food - the cereals. There has been, and continues to be, scepticism about whether increased photosynthetic capacity could actually increase food crop yields ${ }^{2}$. In this issue of Nature Food, Yoon et al. ${ }^{3}$ provide some of the clearest evidence to date that this scepticism may be misplaced. They show that an engineered increase in photosynthetic capacity does, in fact, result in increased grain yield under production field conditions in the world's most important cereal - rice. Rice is a direct source of calories for more people than any other crop, and it serves as the main staple for some 560 million chronically hungry people $e^{4,5}$. The findings presented here therefore have profound importance for food security.

Ribulose 1,5-bisphosphate carboxylaseoxygenase (Rubisco) typically represents $50 \%$ of leaf soluble protein and is the most abundant protein on the planet ${ }^{6}$. While some studies indicate it is present in excess for the requirements of photosynthesis and that it may serve as a storage protein 7 , others have shown it to be co-limiting to light-saturated photosynthesis ${ }^{8}$. However, the close correlation of Rubisco content with chloroplast volume suggested that there is no physical space for yet more of the enzyme in both $\mathrm{C} 3$ and $\mathrm{C} 4$ crops $^{9,10}$. Furthermore, it is anticipated that increased Rubisco production could only be achieved at the expense of nitrogen use efficiency - with consequences for sustainability ${ }^{11}$. Recent analyses of chloroplast volume in C4 crops and a demonstrated transgenic increase in
Rubisco content in maize have disproved the space limitation hypothesis for C4 crops $^{12,13}$ and, now, Yoon et al. ${ }^{3}$ disprove the hypothesis for $\mathrm{C} 3$ rice. Under well-fertilized conditions, the engineered plants showed almost double the flag leaf Rubisco content relative to the untransformed control plants. The corresponding increase in photosynthesis and yield was achieved at the same field nitrogen fertilization level as the controls, so delivering higher nitrogen use efficiency at crop level. The work described here, therefore, challenges a number of paradigms.

In theory, rising atmospheric $\mathrm{CO}_{2}$ concentration increases the velocity of carboxylation by Rubisco, while partially suppressing photorespiration in $\mathrm{C} 3$ crops by competitively inhibiting the oxygenation reaction of Rubisco ${ }^{14}$. However, a near universal effect of the growth of $\mathrm{C} 3$ crops under future elevated $\mathrm{CO}_{2}$ concentrations is a decline in Rubisco content that partially offsets these theoretical gains ${ }^{15}$. Yoon et al. demonstrate a technology for increasing Rubisco, which could offset this loss and maximize the response to rising $\mathrm{CO}_{2}$ concentration, offering a tantalizing insight to a technology that could contribute to future-proofing rice.

While well-known to commercial breeders and agrochemical companies, it seems poorly understood by many plant scientists that plant responses in controlled and other protected environments often differ markedly under field crop-production conditions ${ }^{15,16}$. The authors previous work with these plants in controlled environments actually gave very different results to those of this four-year field study.

These is some way to go in demonstrating that this promising start will translate into other genotypes and environments. Nevertheless, this study is a game-changer in demonstrating a route to substantial sustainable yield increases in an all-important food crop on which so many depend, and on which so many more will depend in the future.

\section{Stephen P. Long (D) ${ }^{1,2}$}

${ }^{1}$ Carl $R$ Woese Institute for Genomic Biology,

University of Illinois at Urbana-Champaign, Urbana, IL, USA. ${ }^{2}$ Lancaster Environment Centre, Lancaster University, Lancaster, UK.

e-mail:slong@illinois.edu

Published online: 18 February 2020 https://doi.org/10.1038/s43016-020-0038-5

\section{References}

1. South, P. F., Cavanagh, A. P., Liu, H. W. \& Ort, D. R. Science 363, eaat9077 (2019).

2. Sinclair, T. R., Rufty, T. W. \& Lewis, R. S. Trends Plant Sci. 24, 1032-1039 (2019)

3. Yoon, D.-K. et al. Nat. Food https://doi.org/10.1038/s43016-0200033-x (2020).

4. Seck, P. A., Diagne, A., Mohanty, S. \& Wopereis, M. C. S. Food Secur. 4, 7-24 (2012).

5. FAO, IFAD, UNICEF, WFP \& WHO The State of Food Security and Nutrition in the World 2017: Building Resilience for Peace and Food Security (FAO, 2017)

6. Bar-On, Y. M. \& Milo, R. Proc. Natl Acad. Sci. USA 116, 4738-4743 (2019).

7. Eichelmann, H. \& Laisk, A. Plant Physiol. 119, 179-190 (1999).

8. Hudson, G. S., Evans, J. R., Voncaemmerer, S., Arvidsson, Y. B. C. \& Andrews, T. J. Plant Physiol. 98, 294-302 (1992).

9. Pyke, K. A. \& Leech, R. M. J. Exp. Bot. 38, 1949-1956 (1987).

10. Sage, R. F., Kocacinar, F. \& Kubien, D. S. in C4 Photosynthesis and Related $\mathrm{Co} 2$ Concentrating Mechanisms (eds Raghavendra, A. S. \& Sage, R. F.) 161-195 (Springer, 2011).

11. Ray, D. et al. Biol. Plantarum 46, 251-256 (2003).

12. Salesse-Smith, C. E. et al. Nat. Plants 4, 802-810 (2018).

13. Pignon, C. P., Lundgren, M. R., Osborne, C. P. \& Long, S. P. J. Exp. Bot. 70, 357-365 (2019).

14. Long, S. P., Ainsworth, E. A., Rogers, A. \& Ort, D. R. Annu. Rev. Plant Biol. 55, 591-628 (2004).

15. Ainsworth, E. A. \& Long, S. P. New Phytol. $\mathbf{1 6 5}$, 351-371 (2005)

16. Garcia-Molina, A. \& Leister, D. Nat. Plants 6, 9-12 (2020). 